\title{
PESQUISA QUALITATIVA EM PSICOLOGIA CLÍNICA: UMA \\ POSSIBILIDADE METODOLÓGICA EM DIÁLOGO COM A \\ FENOMENOLOGIA HERMENÊUTICA
}

\author{
QUALITATIVE RESEARCH IN CLINICAL PSYCHOLOGY: A \\ METHODOLOGICAL POSSIBILITY IN DIALOGUE WITH HERMENEUTIC \\ PHENOMENOLOGY
}

Ellen Fernanda Gomes da Silva ${ }^{1}$

\begin{abstract}
Resumo: O presente artigo, de cunho teórico, apresenta uma proposta metodológica para as pesquisas qualitativas em Psicologia Clínica. Para tanto, discute a perspectiva fenomenológica hermenêutica e suas ressonâncias para a pesquisa qualitativa. Posteriormente, reflete sobre a importância da questão-bússola como norteadora da pesquisa e apresenta a entrevista narrativa e o diário de bordo como recursos metodológicos. Por fim, a análise compreensiva do fenômeno, a partir da compreensão gadameriana, será apontada enquanto possibilidade de compreensão/interpretação do fenômeno a ser pesquisado. Nessa direção, considera-se a relevância dos pressupostos fenomenológicos hermenêuticos - tais como a compreensão, a linguagem, a noção de verdade, fenômeno e método - na tarefa de contribuir para a realização de pesquisas em Psicologia Clínica, ao passo que são assumidos como indicativos-formais; os quais se configuram como sinalizadores de direções e auxiliam na compreensão dos fenômenos.
\end{abstract}

Palavras-chave: Pesquisa Qualitativa; Psicologia Clínica; Fenomenologia Hermenêutica; Gadamer.

\begin{abstract}
This article presents a methodological proposal for qualitative research in Clinical Psychology. For that, we will discuss the hermeneutic phenomenological perspective and its resonances for qualitative research. Later, we will reflect on the importance of the compass question as guiding the research and we will present the narrative interview and the logbook as methodological resources. Finally, the comprehensive analysis of the phenomenon, based on the understanding of Gadamer, will be pointed out as a possibility of understanding / interpretation of the phenomenon to be researched. In this direction, the relevance of hermeneutic phenomenological presuppositions - such as comprehension, language, the notion of truth, phenomenon and method - in the task of contributing to research in Clinical Psychology is considered, while they are assumed as indicative -form; which are configured as direction flags and help in understanding the phenomena.
\end{abstract}

Keywords: Qualitative research; Clinical psychology; Hermeneutic Phenomenology; Gadamer.

\section{Introdução}

Exige-se do pesquisador justamente isto, o mais difícil, a passagem do projeto do homem como ente vivo dotado de razão para ser homem como Dasein. (...). $O$ "deixar" [Lassen], isto é, aceitar [Zulassen] o ente, assim como ele se mostra, só se tornará um deixar-ser apropriado se este ser, o Da-sein, ficar

\footnotetext{
${ }^{1}$ Psicóloga. Doutoranda em Psicologia Clínica pela Universidade Católica de Pernambuco (UNICAP). Pesquisadora do Laboratório de Psicologia Clínica Fenomenológica Existencial (LACLIFE), Recife, Pernambuco, Brasil. E-mail: ellenfernanda1@ @otmail.com
} 
antes e constantemente à vista; isto é, quando o próprio pesquisador tiver experienciado e experienciar-se a si mesmo como Da-sein, como ek-sistente e determinar-se toda realidade humana a partir daí (HEIDEGGER, 1827/2009, p. 263l).

Este artigo tem como objetivo discutir a possibilidade de um caminho metodológico para a pesquisa qualitativa em Psicologia Clínica. Para tanto, propõe-se, de início, uma reflexão sobre a pesquisa fenomenológica hermenêutica; em seguida, será apontada uma possibilidade compreensiva de modalidade de pesquisa em Psicologia Clínica, salientando a importância da questão-bússola e sua função de indicar a direção da pesquisa, bem como o diário de bordo e a entrevista narrativa enquanto recursos metodológicos. Por fim, a partir da perspectiva gadameriana, será tematizado acerca da análise compreensiva do fenômeno.

Nessa direção, o presente estudo teórico configura-se como relevante ao possibilitar uma aproximação da perspectiva fenomenológica hermenêutica com a Psicologia Clínica. Tal pertinência pode ser vista, conforme salienta Silva e Santos (2017) nas pesquisas que vem se desenvolvendo em diversos laboratórios de Psicologia ao longo dos últimos anos, as quais são subsidiadas pela hermenêutica de Heidegger e Gadamer. Justifica-se também por possibilitar outros caminhos investigativos para Psicologia Clínica, à medida que não parte de pressupostos metafísicos e possibilita uma "torção" no modo de compreender o método (hódos- méta). O método se revela, pois, enquanto um caminho inesperado, que se faz no próprio caminhar com a experiência dos participantes da pesquisa e com as contribuições das perspectivas teóricas, as quais são tidas como lentes que ampliam as pré-compreensões dos pesquisadores e auxiliam na tarefa compreensiva dos fenômenos.

Importa destacar que a presente reflexão se inscreve em uma das possibilidades de realização de investigações qualitativas, as quais se caracterizam por se debruçar sobre a complexidade do fenômeno em questão. Nessa perspectiva os elementos estão implicados, simultaneamente, em diferentes processos constitutivos do todo, podendo mudar em face do horizonte em que aparecem. A história e o contexto que caracterizam o público da pesquisa marcam sua singularidade, a qual é expressão da riqueza e plasticidade do fenômeno (GONZÁLEZ REY, 2005).

Frente às diversas modalidades de pesquisa qualitativa, destacamos a perspectiva fenomenológica hermenêutica, a qual se aproxima da compreensão interpretativa indicada na ontologia heideggeriana. Tal caminho metodológico é aqui ressaltado por se revelar em sintonia com uma perspectiva que privilegia a compreensão da experiência e 
por partir de uma interrogação (questão-problema) e acompanhá-la na mostração do fenômeno.

Nessa direção, cabe enfatizar que Heidegger é conhecido como um pensador que questionou a tradição metafísica, na qual o método ganha destaque como simples técnica de pesquisa, procedimento que busca a objetificação/mensurabilidade dos objetos. A Analítica Existencial aponta outro modo de aproximação e compreensão dos fenômenos da existência, distante da objetificação-natural, considerando aquilo que é singular.

A partir de pressupostos fenomenológicos hermenêuticos, o método é salientado em seu sentido original, preservado na etiologia meta-hodos, é "o caminho que leva a algo, uma área, o caminho pelo qual estudamos um assunto" (HEIDEGGER,1987/2009, p. 139). Tal esclarecimento nos direciona a indicar que uma pesquisa que assume a fenomenologia constrói seu método no próprio caminhar do processo investigativo; situando a amplitude, os limites e os contornos do que será estudado.

De acordo com González Rey (2005), reconfigurações do método, ao longo do trânsito do pesquisador pelo campo, são possíveis e mesmo esperadas, não constituindo falta de rigor, mas sim, flexibilidade. Essa "atitude flexível” do pesquisador, atravessada pelas afetações da experiência e pelas necessidades que podem surgir progressivamente, distancia-se da tentativa de controle dos fenômenos.

Outro aspecto que cabe salientar são as ressonâncias do pensamento heideggeriano para pensar o caminho da pesquisa. A partir desse referencial, o método fenomenológico dirige-se ao real, reconhecendo o seu caráter fenomênico. Revela-se também uma outra compreensão de ser, de tempo, de mundo, de linguagem e verdade. A pesquisa de orientação fenomenológica também parte da compreensão de que os fenômenos só podem ser vistos na própria existência, em sua singularidade. Como essa perspectiva também é hermenêutica, a experiência é considerada como condição própria do existir humano. Logo, "não há uma medida nem aquém, além desse fazer. Trata-se de um saber específico que se conquista no próprio fazer - ofício - experiência" (FEIJOO, 2017, p. 83).

Feitos os esclarecimentos iniciais acerca da pesquisa qualitativa e da orientação fenomenológica hermenêutica, faz-se necessário um maior aprofundamento a respeito do que se compreende por essa perspectiva.

\section{Pesquisa fenomenológica hermenêutica: caminhos e desafios}


Ao considerarmos a crítica de Heidegger ao método científico-natural para o estudo dos fenômenos humanos, podemos perceber que seu pensamento contribui para outro modo de pesquisar: distante de modelos teórico-explicativos, da linguagem como mero instrumento para a representação da realidade, e da noção de verdade enquanto adequação e correspondência, sustentada pela precisão metodológica do conceito.

Compromissado em adotar outros pontos de partida mais originários, quem pesquisa inicia sua investigação interrogando o fenômeno, sendo "convidado" ao estranhamento, a afetação diante daquilo que se mostra. O pesquisador é também desafiado a manter um olhar fenomenológico atento ao mostrar-se do fenômeno sem buscar explicações conceituais.

A noção de fenômeno é primordial quando se trata de tal modalidade de pesquisa. Na Analítica Existencial, fenômeno se refere a tudo o que se mostra em si mesmo, o que pode ser visto "sob à luz do dia". Ora, o fenômeno pode se revelar de várias maneiras; há até a possibilidade de se mostrar como aquilo que não é. Importa esclarecer que os homens se mostram de modo peculiar aos demais entes da natureza - "diferença que a metafísica desfaz ou suprime, fazendo com que tudo o que há seja possível de uma e mesma forma de contemplação e definição" (CRITELLI, 2007, p.52).

Tal condição dirige o pesquisador a duas reflexões: primeiro, nenhum saber é absoluto e definitivo, pois a abertura que o homem é permanece como possibilidade e riqueza da existência. Assim, o modo de conhecer da perspectiva fenomenológica hermenêutica é provisório e passível de revisão, modificação; buscando acolher a fluidez e impermanência do existir. Em segundo lugar, as representações conceituais conhecimento válido e fidedigno pela tradição metafísica - não são suficientes para contemplar a dinâmica fenomênica de mostrar-se e ocultar-se.

Seguindo essas pistas, uma pesquisa "inspirada" na fenomenologia hermenêutica se articula no âmbito da existência e não da mera conceituação. Como expõe Critelli (2007, p.151), ao pesquisador cabe uma interpretação do real que "não é uma façanha lógico-conceitual, mas uma possibilidade de compreensão". Desse modo, não buscamos aplicar respostas já sabidas a respeito do fenômeno. "Ao contrário, é a ele que perguntamos o que queremos saber dele mesmo" (p.27). E, assim, lançamo-nos interrogantes em direção àquilo que apela, que afeta, que provoca interesse e almejamos compreender. 
Mas o que se entende por compreensão nessa perspectiva? Diferentemente da tradição usual de uma função meramente cognitiva como "tomar consciência de", Heidegger (1927/2012) apresenta a compreensão como modo originário do Dasein, indicando que o homem não tem uma compreensão, sempre existe a partir dela. É por meio da compreensão que a existência é interpretada ao se expressar em sua história.

$\mathrm{Na}$ perspectiva fenomenológica hermenêutica a compreensão é tida como construção contínua. Tal circularidade realça que não seguimos linearmente em um sentido progressivo, mas ek-sistimos e compreendemos em um vaivém incessante. A noção gadameriana de jogo nos auxilia a refletir o modo como o círculo hermenêutico se movimenta. Para Gadamer (1986/2012), o jogar se caracteriza por um ir e vir sem ponto de partida e chegada. O jogo é, pois, "o vaivém de um movimento que não fixa em nenhum alvo que termine [...] mas que renova-se a cada repetição" (p.156).

Todo jogar é um "ser-jogado" e, portanto, o atrativo do jogo encontra-se no fato de que o jogo se assenhora do jogador. Isto é, a sua razão de ser não é o sujeito, o sujeito do jogo é o próprio jogo. O sentido de jogar também pressupõe um movimento de participação, engajamento, no qual o jogar é a priori um jogar junto. No vaivém próprio ao movimento jogo-compreensão, há sempre uma relação com a alteridade, preservando o mistério, a surpresa.

Aqui cabe interrogar: quais as implicações dessa perspectiva gadameriana para a pesquisa fenomenológica hermenêutica? Possibilita o entendimento do fenômeno estudado como um movimento contínuo, inconcluso e, portanto, aproximativo. Tal compreensão também pressupõe uma atitude de receptividade, acompanhando a contação da experiência. Trata-se de um processo hermenêutico de produção e interpretação a partir da experiência vivida, envolvendo colaboradores e pesquisadores. Nessa perspectiva, a compreensão não está articulada a uma verdade constituída previamente como conhecimento verificável, adequação do real - veritas. O sentido de verdade aproxima-se de alethéia enquanto desencobrimento, trazer à luz. Caminhando em tal direção, não é possível tomar a questão de uma pesquisa como um objeto em si mesmo e sobre ele aplicar uma teoria psicológica ou filosófica. Como a experiência não é um objeto simplesmente dado, mesmo que os protocolos de pesquisas fossem seguidos à risca, ainda assim a experiência escaparia às tentativas de apreensão/controle.

Mantendo-nos na proposta metodológica da fenomenologia hermenêutica, não procurar o sentido da experiência na precisão conceitual se configura uma tarefa desafiante, pois requer um movimento diferente dos métodos de pesquisa já consolidados 
nas ciências humanas e da saúde e um exercício constante de questionar os sentidos sedimentados pelo mundo. Desse modo, as possibilidades compreensivas desveladas a partir da questão-problema de uma pesquisa, não podem ser encontradas no pensamento representacional. Onde então encontrá-las?

\begin{abstract}
O ser das coisas (o que são, como são) não está consumado na sua conceituação, mas também não está incrustado nas próprias coisas, ensimesmadas. Está no lidar dos homens com elas e no falar, entre si, dessas coisas e dos modos de lidar com elas. Está entre os homens e as coisas; está numa trama de significados que os homens vão tecendo entre si mesmos e através da qual vão se referindo e lidando com as coisas e com tudo o que há (CRITELLI, 2007, p.18).
\end{abstract}

Esse modo de pesquisar não supõe uma "neutralidade" do pesquisador e tampouco considera possível que assim se faça, visto que, no jogo compreensivo, o pesquisador está sempre implicado. A tradição científica propõe a separação sujeito/objeto, supondo atingir um conhecimento objetivo a partir do controle das variáveis. Numa pesquisa fenomenológica, por sua vez, investigar um fenômeno é estar envolvido no que ocorre, de modo que o próprio campo de pesquisa afeta o pesquisador; bem como a presença do pesquisador naquela situação de pesquisa pode modificar o que é investigado. Aqui nos deparamos com a noção de afetabilidade - tonalidade afetiva que nos sintoniza com o mundo, revela o modo como estamos situados (HEIDEGGER, 1927/2012).

Após as breves discussões a respeito da pesquisa fenomenológica hermenêutica, uma questão surge: como dizer de uma experiência de pesquisa em um texto? Como descrever o que se revelou, sem que isso recaia na tarefa de explicar? É preciso um esforço genuíno para tematizar a partir de uma linguagem originária que abarca a dimensão do que se apresenta. A palavra da qual nos referimos é a dos relatos, que revelam o sentido do existir. Nessa perspectiva, buscamos, sustentar a "tensão" entre a linguagem teorética e a meditativa. Para tanto,

\begin{abstract}
será preciso desacostumar-se de apenas ouvir e prestar ouvidos àquilo que já se sabia de antemão; será preciso expor-se a um domínio estranho, e não haverá genuína experiência de pensamento senão nessa exposição ao estranho. [...] Tal pensamento e linguagem estranhos tentam experimentar e acolher o simples acontecimento-apropriativo (Ereignis) do ser (DUARTE, 2010, p. 396-397).
\end{abstract}

\title{
3 Para compreender a experiência: possibilidades de percorrer o caminho
}

O senhor poderia me dizer, por favor, qual o caminho que devo tomar para sair daqui? Isso depende muito de para onde você quer ir, respondeu o Gato. Não me importo muito para onde, retrucou Alice. Então não importa o caminho que você 
escolha, disse o Gato. Contanto que dê em algum lugar, Alice completou. (Alice no País das Maravilhas - Lewis Carroll)

Mediante o diálogo com alguns fundamentos da perspectiva fenomenológica hermenêutica de realizar pesquisa, é possível compor um percurso metodológico, a partir do qual pode se encaminhar considerações a respeito dos procedimentos que podem ser adotados em uma investigação. Importa indicar que tal percurso não dispõe de uma metodologia previamente definida; o caminho vai se fazendo no próprio caminhar, na aproximação e no repouso demorado junto ao fenômeno interrogado, aos colaboradores da pesquisa e aos fios teóricos apontados como "interlocutores".

\subsection{A questão-bússola indicando o caminho}

As pesquisas se originam a partir de uma questão, de fenômenos que se apresentam e requerem uma reflexão, um situar-se. Nessa direção, pesquisar é uma construção, uma busca por compreensão. E cada questão a ser investigada abrange diversos pontos de vista e pode levar a diferentes maneiras de pesquisar.

Interessante mencionar que a questão de pesquisa tem um tom singular para cada pesquisador. Diz daquilo que nos chama atenção em um determinado momento. Para Critelli (2007, p. 149, grifos da autora), ao lançar-se no conhecimento de algo, "o interrogador faz parte do que ele quer saber e do que ele pode ver. Ele é elemento constituinte desse olhar em que tudo o que é tem sua chance de aparecer, mesmo que como mera testemunha". Esse olhar do pesquisador é, ao mesmo tempo, exclusivo e plural - no qual se expõe a sua singularidade, mas não é algo isolado, diz também daqueles com quem ele mesmo é no-mundo.

Uma pesquisa assim compreendida é tida como autoral, partindo da experiência do pesquisador e desdobrando-se no contexto social/acadêmico. Portanto, a atitude fenomenológica apresenta-se sempre afetada, implicada. "A intrínseca relação apontada entre o sujeito que pesquisa e o seu 'objeto', provocando a impossibilidade de uma objetividade neutra ou de uma subjetividade anulada, fundamenta um modo mais flexível diante do processo de construção do conhecimento" (CABRAL; MORATO, 2013, p. 167).

É oportuno realçar a importância da questão de pesquisa como etapa primordial para o desdobramento de uma investigação, de maneira a ser caracterizada por Cabral e Morato (2013) como bússola que norteia, orienta, indicando caminhos possíveis para 
levar a investigação adiante. Tal questão vai se mostrando de maneira mais clara, ganhando contornos mais precisos ao longo do aprofundamento no tema em que se quer pesquisar e/ou no trânsito, afetação do pesquisador no campo/instituição em que está inserido.

Cabe também mencionar que a questão-bússola está voltada a compreender a experiência. Desse modo é aberta, possibilitando com o que os colaboradores da pesquisa possam narrar livremente. Nessa perspectiva, outras perguntas podem ser realizadas, a fim de uma melhor compreensão do fenômeno em questão e abrindo caminhos para refletir a questão-bússola e aprofundá-la a partir de outros horizontes. Em tal modo de pesquisa não só se descobre aquilo que se busca, pois surgem elementos "inesperados", os quais podem ser relevantes para o processo de construção do conhecimento.

Tendo a questão-bússola como norteadora, a pesquisa se constrói na medida em que é trilhada. E, nesse percurso, não se almeja chegar a um lugar pré-determinado, nem se tem como fixo o caminho a percorrer. Assim, cada momento da pesquisa vai se delineando ao longo do pesquisar. É fundamental salientar que o próprio trânsito da pesquisa "sinalizará rotas pertinentes, na proporção que o pesquisador vai se afetando pelas descobertas ao longo do caminho, melando-se na própria experiência de pesquisar, o que poderá reorientar os rumos do pesquisar" (CABRAL; MORATO, 2013, p.171).

Como vimos, uma questão de pesquisa nasce de uma interrogação, um estranhamento que determinado fenômeno suscita. Revelado o que merece ser interrogado, há a necessidade de refletir a respeito dos caminhos possíveis para pôr a caminho a interrogação. Da articulação entre experiência (que gera uma questão-bússola) e a narrativa (matéria-prima da experiência, forma artesanal de comunicação), fundamenta-se, a seguir, a importância de dois recursos metodológicos: a entrevista narrativa e o diário de bordo.

\subsection{Recursos metodológicos}

Por recursos metodológicos compreendemos os procedimentos que permitem o pesquisador e os colaboradores expressarem-se no contexto que caracteriza a pesquisa. Tais recursos são ferramentas interativas, suscetíveis a uma multiplicidade de usos no processo investigativo.

Na tradição positivista da pesquisa em Psicologia, o uso de instrumentos tornouse em um fim em si mesmo dada a capacidade atribuída a eles para produzir resultados 
finais, suscetíveis de serem utilizados como entidades objetivas no processo de análise. A ideia de objetividade do conhecimento se associou estritamente ao uso de instrumentos validados, confiáveis e generalizados; assim, a legitimidade da informação, o valor da pesquisa depende de sua procedência instrumental (GONZÁLEZ REY, 2005).

Na perspectiva fenomenológica hermenêutica, por sua vez, os colaboradores da pesquisa fazem mais do que responder ante a um "instrumento", eles se expressam por meio dele, tematizam acerca de sua experiência e podem elaborá-la à medida que vão narrando. Tanto os colaboradores como o pesquisador compartilham suas experiências, dúvidas e tensões, em um processo que facilita o emergir de sentidos no curso da conversação.

"O uso de instrumentos abertos facilita a expressão do sujeito em toda a sua complexidade e aceita o desafio que implica a construção de ideias e conceitos sobre a informação diferenciada que expressam os sujeitos estudados (GONZÁLEZ REY, 2005, p. 81-82). Em ressonância com a Fenomenologia Hermenêutica iremos indicar dois recursos metodológicos que podem ser utilizados em pesquisa qualitativa. No primeiro deles, a entrevista narrativa, é possível uma aproximação com a experiência dos colaboradores da pesquisa. Para tanto, a conversação é iniciada com uma questão-bússola, a qual serve de abertura e de guia para que os colaboradores narrarem suas experiências. O segundo recurso a ser mencionado será o diário, o qual contempla os testemunhos da experiência do pesquisador, seja em sua experiência clínica e/ou sua afetação no campo da pesquisa. Desse modo, o próprio pesquisador é, também, uma participante da pesquisa.

A seguir, para uma melhor compreensão iremos nos deter, mesmo que brevemente, na tematização destes recursos.

\section{- Entrevista narrativa}

Conforme Flick (2009), a entrevista narrativa caracteriza-se por não ser estruturada, rompendo com a tradição de entrevistas baseadas em perguntas e respostas. Inicia-se por uma questão-bússola que objetiva estimular a narrativa da experiência do entrevistado. As intervenções que possam surgir durante o momento da entrevista acompanham o fluxo da própria narrativa, de modo a estimular questões relevantes à pesquisa que não tenham sido narradas e/ou clarear dimensões que ficaram obscuras à compreensão do pesquisador. 
A entrevista narrativa é considerada um recurso relevante para compreender qualitativamente determinado fenômeno, favorecendo ir além da transmissão de informações. Ao propor que os colaboradores discorram, livremente, acerca de sua experiência, nos desprendemos da tendência de controlar e explicar o discurso, o que pode propiciar a construção de uma narrativa, com profundidade e comprometida com o vivido.

Interessante mencionar que há nas entrevistas narrativas uma característica colaborativa entre entrevistados e pesquisador. Com uma escuta implicada, o pesquisador atenta para o discurso, o silêncio, a tensão, o ritmo dos colaboradores; já o entrevistado, voltado a narrar sobre o que viveu, tem a possibilidade de refletir, tematizar e se apropriar da experiência.

\section{- Diário de bordo}

Para Machado (2002), o diário de bordo configura-se uma "ferramenta fenomenológica" de pesquisa, visto que comunica, em palavras, a experiência do pesquisador a respeito de determinado fenômeno ou situação; proporcionando, assim, um espaço meditativo ao passo que se aproxima e se afasta da experiência vivida.

Seguindo tal direção, Aun e Morato (2009) compreendem diários de bordo como depoimentos rememorados, relatos e testemunhos do vivido. Interessante notar que essa forma de registro ultrapassa um simples relatório descritivo, pois imprime as marcas que surgiram no percurso da investigação do fenômeno - expressa sentimentos, denuncia questionamentos provocadores e angústias.

Nessa direção, os diários de bordo “[...] não são apenas possibilidade de restituição da historicidade de uma pesquisa; são também, o narrar a biografia da experiência de um profissional, na perspectiva de quem comunica como ocorreu o revelar-se do outro a esse profissional/pesquisador" (AUN; MORATO, 2009, p.123). A narrativa da experiência é a matéria-prima dessa modalidade de investigação.

O diário de bordo se apresenta como companheiro de viagem frente às paisagens, descobertas, estranhamentos e aos mistérios que podemos nos deparar durante o percurso de pesquisa. De modo autoral, reflexivo e até mesmo confessional, o pesquisador relata o vivido, rememora e comunica a experiência através de narrativas escritas de próprio punho. O pesquisador é, pois, testemunha, co-participante da experiência narrada. 


\section{Análise hermenêutica-compreensiva do fenômeno}

Vimos que a Hermenêutica Filosófica almeja interrogar o fenômeno que se mostra, revelando uma análise compreensiva da ação humana. Tal análise é construída a partir do jogo dialógico entre entrevistando e entrevistador, abrindo para possibilidades compreensivas. Importa mencionar que, no processo de análise das entrevistas narrativas e do diário de bordo, recorremos a algumas dimensões do pensamento gadameriano na tentativa de compreender como a angústia ressoa/atravessa a ação clínica de psicólogos.

De início, adotamos a noção de tradição, na qual nos encontramos sempre inseridos, "e essa não é uma inserção objetiva, [...] trata-se sempre de algo próprio" (GADAMER 1986/2012, p. 374). Numa pesquisa fenomenológica hermenêutica, a tradição se faz presente, seja no diálogo com os colaboradores entrevistados ou no diálogo com a narrativa do diário de bordo. Podemos dizer que a compreensão se dá por compartilhamos do "grande horizonte" da tradição, que engloba o vigor do presente, do passado e do futuro. Esse é o horizonte onde se dá "a vida humana" e que a constitui enquanto tradição.

Partindo da perspectiva de círculo hermenêutico, Gadamer (1986/2012) realça a compreensão como um jogo no qual se dá "o intercâmbio entre o movimento da tradição e o movimento do intérprete" (p. 388). Desse modo, a "antecipação de sentido, que guia nossa compreensão de um texto, não é um ato da subjetividade, já que se determina a partir da comunhão que nos une com a tradição. [...] essa comunhão é concebida como um processo aberto, em contínua formação" (p.388).

Notamos, assim, que a compreensão de tradição, pertence a noção de horizonte. Horizonte, é "o âmbito de visão que abarca e encerra tudo o que pode ser visto a partir de determinado ponto". Nessa perspectiva, é possível falar da "estreiteza de horizonte, da possibilidade de ampliar o horizonte, da abertura de novos horizontes etc." (GADAMER 1986/2012, p. 399). Na pesquisa de cunho fenomenológico hermenêutico, horizonte se apresenta como algo aberto à nossa frente; é, essencialmente, mobilidade. O diálogo com o outro ocorre quando nos aproximamos e acolhemos seu horizonte, sendo também afetados por ele. Aqui realçamos a vinculação que nossa experiência de homem e de mundo tem no percurso do pesquisar - "como viajantes, sempre voltados para casa com novas experiências" (p.578).

Gadamer (1986/2012) esclarece que um diálogo parte das compreensões de mundo dos envolvidos na conversação; e essa pré-compreensão está atravessada pela 
tradição e preconceitos, os quais podem limitar a compreensão, mas também, quando tematizados e apropriados, tornam-se "mola propulsora". $\mathrm{Na}$ análise compreensiva do fenômeno investigado, interpretamos a partir desse horizonte previamente aberto, no qual nos movimentamos.

Interessante destacar que uma questão de pesquisa tem sempre uma orientação ao que se propõe investigar. Nessa direção, o problema de pesquisa já se encontra sob determinada perspectiva, não como uma visão que se mantém e se impõe. A perguntadisparadora das entrevistas a serem realizadas tem o caráter de descoberta, do estar descobrindo junto aos colaboradores a riqueza de suas experiências. As compreensões que se apresentaram desse diálogo não são definitivas, mas abertas ao contínuo dialogar.

Gadamer realça que o objetivismo histórico buscou encobrir a historicidade da compreensão, se distanciando do horizonte da tradição. O autor ressalta a necessidade de um esforço em direção à tarefa hermenêutica, visto que a compreensão implica num deslocamento para um horizonte comum. Em outros termos, compreender se dá numa "fusão de horizontes" (Horizontverschmelzung); mantendo a coexistência, a tensão entre a tradição e o presente, entre o nosso horizonte e o dos colaboradores, sem que ambos sejam vistos separadamente.

A análise compreensiva do fenômeno é, pois, resgatando um termo gadameriano, a realização da conversação, em que é expresso algo comum, que não é só meu ou do outro. Nessa fusão e seguindo a direção da pergunta-disparadora, é possível ampliar nossa compreensão a respeito da temática de investigação.

\begin{abstract}
Como uma palavra puxa a outra, como a conversa toma seus rumos, encontra seu curso e seu desenlace, tudo isso pode ter algo como uma direção, mas nela não são os interlocutores que dirigem: eles são os dirigidos. O que "surgirá" de uma conversação ninguém pode saber de antemão. $\mathrm{O}$ acordo ou seu fracasso é como um acontecimento que se realiza em nós. [...] compreender o que alguém diz é pôr-se de acordo na linguagem e não transferir-se para o outro e reproduzir suas vivências (GADAMER, 1986/2012, p. 497).
\end{abstract}

No acordo da conversação é necessário que "os interlocutores estejam dispostos a isso, abrindo espaço para acolher o estranho e o adverso" (GADAMER, 1986/2012, p.501). Nessa direção, persistimos em resguardar o tom singular da experiência e manter a receptividade ao mistério. Quando pesquisador e colaboradores se colocam na pesquisa dessa maneira, é possível chegar a uma linguagem comum. Frente a isso, importa acentuar que,

o mundo é o solo comum, não palmilhado por ninguém e reconhecido por todos, que une a todos os que falam entre si. Todas as formas da comunidade de vida humana são formas de comunidade linguística, e, mais ainda, formam linguagem. Isso porque a linguagem não é por sua essência a linguagem da 
conversação. Ela só adquire sua realidade quando se dá o entendimento mútuo. Por isso, não é um simples meio de entendimento (GADAMER, 1986/2012, p.576).

A linguagem da conversação, que interroga a dicotomia sujeito/objeto ainda comum no campo da pesquisa em Psicologia, se reveste de uma importância fundamental para a elaboração da análise das narrativas. O desvelamento do fenômeno se configura como as primeiras afetações da pesquisadora diante da escuta/acolhimento das narrativas recolhidas nas entrevistas e nos registros do diário de bordo. Buscando tematizar as afetações, lançamo-nos em direção à experiência que se busca conhecer. Por essa via, as interpretações são costuradas pelos fios teóricos que se apresentaram desde o início da pesquisa.

Por fim, torna-se pertinente apontar que o sentido de uma pesquisa fenomenológica hermenêutica nunca se esgota, podendo ser compreendido mais uma vez, por outro olhar. O que nos sinaliza que a tarefa hermenêutica, em forma de espiral, está em constante movimento e resiste ao obscurecimento pela generalização do fenômeno.

\section{Considerações finais}

Este artigo buscou apontar a relevância dos pressupostos fenomenológicos hermenêuticos para a pesquisa qualitativa no campo da Psicologia Clínica. A partir do que foi refletido, podemos ressaltar um modo fenomenológico de pesquisar; o qual questiona juízos predicativos, teorizações já dadas e revela-se como possibilidade de, a partir da experiência mesma, apontar possibilidades compreensivas a respeito do fenômeno pesquisado.

Para dizer dessa aproximação com a experiência, empenha-se em utilizar uma linguagem descritiva, própria de um posicionamento estranho aos nossos dias. Tal escolha objetiva um certo distanciamento do discurso vinculado à razão, o qual pode comprometer o sentido primeiro da experiência e levar a conclusões apressadas e desinteressadas pela vida mesma.

Em diálogo com o pensamento de Heidegger, é possível falar de um deixar vir à luz, um convite a ser norteado pela questão-bússola da pesquisa, a acompanhar os colaboradores da pesquisa em sua caminhada, conhecer sua opinião, seus questionamentos; estar próximo ao fenômeno investigado em seu próprio movimento de 
acontecer. Este "movimento fenomenológico" é compreendido como um grande desafio: recuar à tendência explicativa!

É preciso nos voltarmos continuamente para o fenômeno a fim de ver o que se mostra, como uma testemunha que observa e deixa acontecer. Mantendo-nos nessa tensão, revela-se um compromisso ético de divulgar as narrativas colhidas e de manter uma proximidade com o fenômeno estudado, ressaltando seu vigor.

Tal modo de pesquisar se configura como um trabalho artesanal compartilhado que acolhe o modo de ser, a afetação e a experiência narrada pelo pesquisador e pelos colaboradores da pesquisa. Interessante mencionar que os "fios teóricos" atravessam todo o percurso do trabalho, mas não o determinam previamente. Nessa direção, os pressupostos fenomenológicos hermenêuticos podem contribuir para a realização de uma pesquisa em Psicologia Clínica ao serem assumidos como indicativos-formais; os quais se configuram como sinalizadores de direções e auxiliam na tarefa de ver e compreender os fenômenos.

\section{Referências}

AUN, H. A.; MORATO, H. T. P. Atenção Psicológica em Instituição: Plantão Psicológico como Cartografia Clínica. In: MORATO, H. T. P.; BARRETO, C. L. B. T.; NUNES, A. P. (Orgs.). Aconselhamento Psicológico numa Perspectiva Fenomenológica Existencial: uma introdução. 1. ed. Rio de Janeiro: Guanabara Koogan, 2009. p. 123-138,

CABRAL, B. E.; MORATO, H. T. P. A questão de pesquisa como bússola: notas sobre o processo de produção de conhecimento em uma perspectiva fenomenológica existencial. In: BARRETO, C. L. B. T.; MORATO, H. T. P.; CALDAS, M. T. (Orgs.). Prática Psicológica na Perspectiva Fenomenológica. 1. ed. Curitiba: Juruá, 2013. p. 159-181.

CRITELLI, D. M. Analítica do Sentido: uma aproximação e interpretação do real de orientação fenomenológica. 2. ed. São Paulo, SP: Brasiliense, 2007.

DUARTE, A. Vidas em risco: crítica do presente em Heidegger, Arendt e Foucault. 1. ed. Rio de Janeiro: Forense Universitária/GEN, 2010.

FEIJOO, A. M. L. C. Existência \& psicoterapia: da psicologia sem objeto ao saber fazer da clínica psicológica existencial. 1. ed. Rio de Janeiro: IFEN, 2017.

FLICK, U. Introdução a Pesquisa Qualitativa. 3. ed. São Paulo: Artmed, 2009.

GADAMER, H-G. Verdade e Método I: traços fundamentais de uma hermenêutica filosófica. 12. ed. Petrópolis: Vozes, 1986/2012.

GONZÁLEZ REY, F. L. Pesquisa qualitativa em psicologia: caminhos e desafios. 2. ed. São Paulo: Thomson Pioneira, 2005. 
HEIDEGGER, M. Seminários de Zollikon. 2. ed. Petrópolis: Vozes, 1987/2009.

HEIDEGGER, Martin. Ser e tempo. 7. ed. Petrópolis: Vozes, 1927/2012.

MACHADO, M. M. O Diário de Bordo como ferramenta fenomenológica para o pesquisador em Artes Cênicas. Sala Preta, São Paulo, v. 2 n. 1, p. 260-263, 2002.

SILVA, E. F. G. da.; SANTOS, S. E. de B. Fenomenologia existencial como caminho para a pesquisa qualitativa em Psicologia. Rev. Nufen: Phenom. Interd, Belém, v. 9, n.3, p.110-126, set./dez. 2017.

Recebido em: 23 de janeiro de 2018.

Aceito em: 02 de julho 2018. 